\title{
RELIGIÃO E PERSONALIZAÇÃO. LIPOVETSKY E A SOCIEDADE HIPERMODERNA.
}

\section{- FABIANO VELIQ ${ }^{1}$}

1'Doutor em Psicanálise pela PUC Minas. Mestre em Filosofia da Religião pela FAJE. Especialista em Teologia sistemática pela Faculdade Batista de Minas Gerais. Graduado em Filosofia pela UFMG. Professor Adjunto do Departamento de Filosofia da PUC-MG.

Recebido em: 25/10/2018

Aprovado em: 23/05/2019

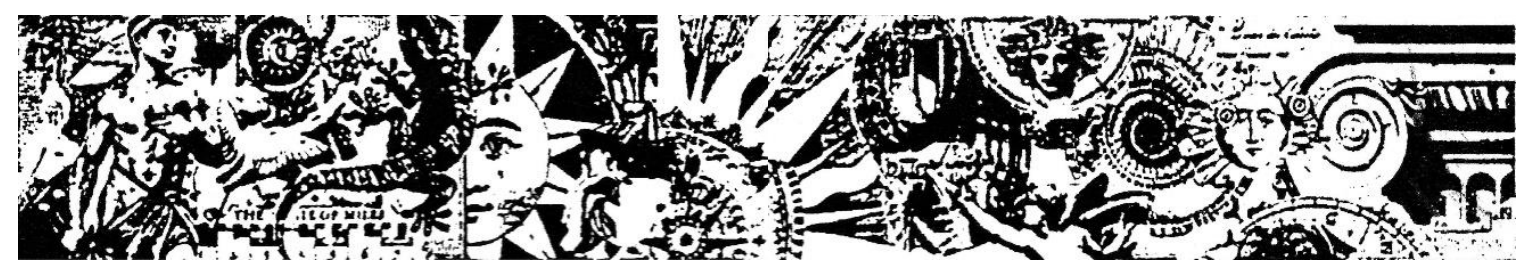

Resumo: O presente artigo tem em vista analisar a proposta de Gilles Lipovetsky que caracteriza a nossa época como a época hipermoderna a partir do processo de personalização. Procuramos evidenciar neste artigo que tal processo de personalização conduz a um individualismo que se manifesta de forma nítida em uma dinâmica consumista interferindo na relação do sujeito com a sociedade e ao mesmo tempo procuramos evidenciar em que medida a religião será vivenciada neste contexto.

Palavras-chave: Personalização, Individualismo, Hipermodernidade, Religião.

\section{RELIGION AND PERSONALIZATION. LIPOVETSKY AND THE HYPERMODERN SOCIETY.}

Abstract: The present article aims to analyze the proposal of Gilles Lipovetsky that characterizes our time as the hypermodern era from the process of personalization. We try to show in this article that such a process of personalization leads to an individualism that is clearly manifested in a consumerist dynamic interfering in the relationship between the subject and society and, at the same time, we intent to evidence in what measure the religion will be lived in this context.

Keywords: Personalization, Individualism, Hypermodernity. 


\section{RELIGIÓN Y PERSONALIZACIÓN. LIPOVETSKY Y LA SOCIEDAD HIPERMODERNA.}

Resumen: El presente artículo tiene por objeto analizar la propuesta de Gilles Lipovetsky que caracteriza a nuestra época como la época hipermoderna a partir del proceso de personalización. En este artículo se busca evidenciar que tal proceso de personalización conduce a un individualismo que se manifiesta de forma nítida en una dinámica consumista interfiriendo en la relación del sujeto con la sociedad y al mismo tiempo procuramos evidenciar en qué medida la religión será vivenciada en este contexto.

Palabras clave: Personalización, Individualismo, Hipermodernidad, Religión

\section{Introdução}

O tema do individualismo é com certeza um tema bastante amplo e seria muita pretensão nossa abarcar toda a discussão desde a sua gênese até o nosso contexto atual, passando por todas as nuances que o termo adquiriu desde a sua formulação por Louis Dumont.

Dumont, como afirmamos acima, foi um dos primeiros sociólogos a trabalhar o conceito de individualismo. Dumont (1985) procurará entender a gênese e a evolução do individualismo na sociedade ocidental. Segundo Dumont,

Eis a minha tese, em termos aproximados: algo do individualismo moderno está presente nos primeiros cristãos e no mundo que os cerca, mas não se trata exatamente do individualismo que nos é familiar. Na realidade, a antiga forma e a nova estão separadas por uma transformação tão radical e tão complexa que foram precisos nada menos de dezessete séculos de história cristã para completá-la, e talvez prossiga ainda em nossos dias. A Religião foi o fermento essencial, primeiro, na generalização da fórmula e, em seguida, na sua evolução. Nos nossos limites cronológicos, o pedigree do individualismo moderno é, por assim dizer, duplo: uma origem ou aceitação de uma certa espécie, e uma lenta transformação numa outra espécie. (DUMONT, 1985, p. 36).

Para Dumont, portanto, o gérmen do individualismo estaria mais próximo dos primeiros cristãos que de outras sociedades. De forma sucinta, para ele,

O individualismo cristão está presente desde a origem sendo que a evolução consiste em um movimento a partir de um individualismo-fora-do-mundo para o individualismo-no-mundo (de forma progressiva), processo no qual a comunidade holista mesma acaba por desaparecer, ou quase desaparece. (DUMONT, 2000, p. 27).

Para ele existiriam dois tipos de sociedade. "Quando o Indivíduo constitui o valor supremo, falo de individualismo; no caso oposto, em que o valor se encontra na sociedade como um todo, falo de holismo." (DUMONT, 1985, p. 37). 
O grande problema para ele era investigar como de sociedades tipicamente holistas surgem sociedades de cunho individualista. Para isso, Dumont propõe uma comparação com a sociedade indiana, onde o caráter holista se mostra de forma bastante visível a partir do conceito de castas. Dumont (1992) analisará a sociedade indiana, mostrando como se dá a relação entre o indivíduo e a sociedade em uma sociedade tipicamente holista.

À medida que suas investigações vão se encaminhando, Dumont é capaz de afirmar que o princípio cristão de que o indivíduo é um ser-em-relação-com-Deus acaba colocando o indivíduo como um indivíduo-fora-do-mundo. A questão se coloca do ponto de vista de um individualismo absoluto, mas ao mesmo tempo em um universalismo absoluto em relação a Deus. A alma individual adquire valor em relação a Deus, e, a partir de uma relação filial dos membros que possuem um mesmo pai através da figura do Cristo, o cristianismo é capaz de desvalorizar o mundo em nome de uma filiação que transcende as instituições sociais.

A fraternidade em torno da figura do Cristo coloca todos os cristãos em um pé de igualdade que existe na presença de Deus. 0 indivíduo-fora-do-mundo se insere em uma comunidade que caminha na Terra, mas tem o seu coração no céu e, dessa forma, o individualismo cristão é capaz de subordinar o holismo. À medida que a igreja passa a assumir o poder e pretende reinar direta e indiretamente sobre o mundo, o indivíduo cristão é chamado a se comprometer com esse mundo de forma completamente nova. O indivíduo-fora-do-mundo se transforma em um indivíduo-nomundo. A exacerbação completa dessa proposta pode ser vista no interior da Teologia da Libertação dos anos 60 do século passado, quando o caráter imanente do mundo, em várias ocasiões, é ressaltado em detrimento da dimensão transcendente.

Esse grande período de transformação da Teologia, desde o início da era cristã até a Teologia da Libertação, não será algo trabalhado por nós no decorrer deste artigo. 0 que procuramos ressaltar a partir desse exemplo é apenas a dinâmica evidenciada por Dumont de uma passagem de um holismo a um individualismo iniciado pelo cristianismo.

Não é novidade para ninguém que a nossa época é fruto de inúmeras mudanças que ainda estão em movimento e, por isso, tornam-se difíceis de ser analisadas de forma mais imparcial. As inúmeras discussões sobre o que de fato caracterizaria a nossa sociedade atual é motivo de inúmeros debates em relação aos melhores termos que caracterizariam a nossa real situação.

Vários sociólogos, filósofos, cientistas políticos discutem sobre qual seria o melhor termo para caracterizar a nossa época. Contemporaneidade, pós-modernidade, hipermodernidade, são termos extensamente debatidos por esses grupos em uma tentativa de definir a nossa época. Por 
mais importantes que sejam tais debates, eles não serão alvos de nossa análise neste trabalho. Quem tiver interesse nessa discussão, sugerimos o excelente livro de Krishan Kumar2, especialmente os capítulos quatro e cinco, em que o autor analisa de forma bastante cuidadosa os diversos termos, os principais defensores de determinado termo, além das justificativas para se adotar um termo em detrimento do outro.

O termo pós-modernidade aparece no final dos anos 70 advindo do discurso da Arquitetura, mas foi rapidamente assimilado pelo discurso das Ciências Sociais, pois indicava uma espécie de "abalo" dos alicerces absolutos e o fracasso das grandes ideologias da história. O que se constatava é que estávamos diante de um novo período histórico, em que a diversidade de opiniões e uma menor expectativa em relação ao futuro davam a tônica. O futuro como lugar de uma realização, como lugar de esperança, era facilmente abandonado em nome de um enfoque cada vez maior no presente.

O termo "pós-moderno" visava definir esse novo momento de fixação no presente, salientando uma mudança de direção no caminho da sociedade, e, ao mesmo tempo, indicar uma reorganização profunda do modo de funcionamento social.

No entanto, a expressão "pós-moderno" logo se via em apuros dada a sua ambiguidade e, ao mesmo tempo, o seu caráter um tanto quanto vago. 0 pós de pós-moderno ainda dirigia 0 seu olhar para o passado, ao mesmo tempo em que afirmava a sua morte. $O$ que atestava isso era o fato de que não se podia falar em uma "mudança de direção", mas sim de uma exacerbação de um modo de vida que teve seu início nos anos 1920. Segundo Lipovetsky e Charles,

Há vinte anos, o conceito de pós-moderno dava oxigênio, sugeria o novo, uma bifurcação maior; hoje, entretanto, está um tanto quanto desusado. O ciclo pós-moderno se deu sob o signo da descompressão cool do social; agora, porém, temos a sensação de que os tempos voltam a endurecer-se, cobertos de nuvens escuras. [...] No momento em que triunfam a tecnologia genética, a globalização liberal e os direitos humanos, o rótulo pós-moderno já ganhou rugas, tendo esgotado sua capacidade de exprimir o mundo que se anuncia. (LIPOVETSKY \& CHARLES, 2004, p. 52).

Se o termo pós-moderno não se aplica para entender nossa dinâmica atual dada a sua ambiguidade, Lipovetsky propõe o termo hipermodernidade para caracterizar uma época em que tudo é hiper. Hipercapitalismo, hiperclasse, hiperindividualismo, hiperterrorismo. Segundo ele, a nossa época se caracteriza por ser uma modernidade elevada a uma potência superlativa, quando a modernização é desenfreada e o ímpeto técnico-científico alcança níveis inimagináveis, que

${ }^{2}$ Cf.KUMAR, Krishan. Da sociedade Pós-Industrial à pós-Moderna. Novas teorias sobre o mundo contemporâneo. Tradução de Ruy Jungmann. Rio de Janeiro: Jorge Zahar Editor, 1997. 
carregam tantos perigos quanto promessas. Tudo acontecendo rapidamente, sem pausas e sem descanso.

Segundo Lipovetsky e Charles,

Longe de decretar-se o óbito da modernidade, assiste-se a seu remate, concretizando-se no liberalismo globalizado, na mercantilização quase generalizada dos modos de vida, na exploração da razão instrumental até a "morte" desta, numa individualização galopante. (LIPOVETSKY \& CHARLES, 2004, p.53).

O que se vê, portanto, não seria tanto uma superação da modernidade, mas uma reconfiguração em que os valores modernos tais como a moral, a revolução, o ideal de Nação se perderam em grande parte e as forças de oposição à modernidade democrática, liberal e individualista não são mais estruturantes, mas em que impera um individualismo e um relativismo em relação a praticamente todas as coisas. O Estado, a Religião, a família se privatizam enquanto a sociedade de mercado se impõe. Ainda segundo Lipovetsky e Charles,

Eleva-se uma segunda modernidade, desregulamentadora e globalizada, sem contrários, absolutamente moderna, alicerçando-se essencialmente em três axiomas constitutivos da própria modernidade anterior: o mercado, a eficiência técnica, o indivíduo. Tínhamos uma modernidade limitada; agora, é chegado o tempo da modernidade consumada. (LIPOVETSKY \& CHARLES, 2004, p.54).

A hipermodernidade se impõe hiperbolizando todas as coisas. Do consumo às viagens, da tecnologia à alimentação. Tudo se torna hiper no mundo onde as mudanças e o mercado sempre estão em crescimento, onde até os comportamentos individuais são levados ao extremo. Prova disso são os esportes em séries, as bulimias, anorexias, obesidades.

A época hipermoderna é também a época das contradições. Se por um lado os indivíduos cuidam cada vez mais do corpo obedecendo às instruções médicas, informando-se sobre o que devem ou não fazer, por outro lado, aumentam as doenças psíquicas, as patologias individuais, o anarquismo comportamental. Lei e liberdade desenganchadas em um quadro no qual 0 hiperindividualismo distanciado do outro toma lugar, ele também paradoxal, pois, ao mesmo tempo em que se mostra prudente e calculista (por exemplo nas questões de saúde, do corpo etc.), ao mesmo tempo se mostra desregrado e caótico.

Segundo Lipovetsky e Charles,

Tudo se passa como se tivéssemos ido da era do pós para a era do hiper. Nasce uma nova sociedade moderna. Trata-se não mais de sair do mundo da tradição para aceder à racionalidade moderna, e sim de modernizar a própria modernidade, racionalizar a racionalização - ou seja, na realidade, destruir os "arcaísmos" e as rotinas burocráticas, pôr fim à rigidez institucional e aos entraves protecionistas, relocar, privatizar, estimular a concorrência. [...] Por toda a parte, a ênfase é na obrigação do movimento, a hipermudança sem o peso de qualquer visão utópica, ditada pelo 
imperativo da eficiência e pela necessidade da sobrevivência. Na hipermodernidade, não há escolha, não há alternativa, senão evoluir, acelerar para não ser ultrapassado pela "evolução": 0 culto da modernização técnica prevaleceu sobre a glorificação dos fins e dos ideais. (LIPOVETSKY \& CHARLES, 2004, p. 56-57).

Podemos notar que a hipermodernidade se caracterizaria como um momento em que 0 excesso e o vazio se enfrentam em uma espécie de combate que gera, ao mesmo tempo, mais autonomia e liberdade ao sujeito, daí o seu caráter de "excesso", mas, em contrapartida, traz novas angústias e problemas e coloca o homem diante desse "novo lugar" que é, por definição, um lugar de vazio, por ser um lugar carente de referências. Isso porque o excesso de liberdade e autonomia acaba por colocar como objetos de questionamento todas as coisas, até mesmo as estruturas que organizam o mundo. Segundo Silva,

A era do vazio é um tempo de comunicação. Não mais da comunicação como conteúdo ou mensagem, no sentido moralizador desse termo, mas comunicação como forma de contato, expressão de desejos, emancipação do jogo utilitário. Gera medo, pânico e até horror uma época em que tudo pode ser questionado. Na realidade, essa desmontagem dos mecanismos de legitimação pela moral rigorista implica uma perda de poder pelos donos das sociedades ou um rearranjo das formas de controle: a manipulação cede lugar à sedução; a imposição deve transformar-se em conquista; cada um deve aderir a um valor, não mais ser obrigado a submeterse a ele. (SILVA apud LIPOVETSKY, 2005, p. 11).

Ou ainda, segundo Lipovetsky,

Devemos recusar tanto as Leituras pós-modernistas, como as Leituras de ficção científica ou de tendência apocalíptica do conforto contemporâneo. Na verdade, este último é simultaneamente high-tech e cultural, virtual e sensível, abstracto e táctil, funcional e emocional, dromocrático (Virilio) e estético. A ruptura face à primeira modernidade não foi, de modo algum, total; sob inúmeros aspectos, o nosso mundo não faz mais que levar ao extremo a dinâmica prometeica. Aquilo a que assistimos não é tanto o emergir de uma cultura "pós-moderna", mas fundamentalmente uma hipermodernização do conforto dominado pelo crescendo do tempo e da rapidez, pela excrescência do mercado e da oferta. (LIPOVETSKY, 2007, p. 196).

A chave de Leitura lipovetskiana para analisar a hipermodernidade é o conceito de personalização. Para ele, a partir do momento em que as sociedades democráticas se desenvolvem, acontece um remodelamento constante e profundo dos setores da vida social. Esse processo é denominado como processo de personalização. Segundo Lipovetsky,

O processo de personalização procede de uma perspectiva comparativa e histórica, determina a linha diretiva, o senso do novo, o tipo de organização e de controle social que nos liberta da ordem disciplinar-revolucionária-convencional que prevaleceu até o decorrer da década de 1950. Ruptura com a fase inaugural das sociedades modernas, democráticas-disciplinares, universalistasrigoristas, ideológicas-coercitivas, este é o sentido do processo de personalização [...] Trata-se de uma mutação sociológica global que está em curso, uma criação histórica próxima daquilo que Castoriadis chama de "significação imaginária central", combinação sinérgica de organizações e 
significados, de ações e valores, que vem se formando a partir da década de 1920 - apenas as esferas artísticas e psicanalíticas a anteciparam em alguns decênios - e que continuou a ampliar seus efeitos depois da segunda guerra mundial. (LIPOVESTKY, 2005, p. 16).

Se por um lado tal processo de personalização se mostra como um avanço em direção a uma sociedade mais igualitária, mais flexível, baseada na informação e na consideração dos fatores humanos, negativamente tal processo remete à fratura da socialização disciplinar, quando os valores são todos colocados em xeque, deixando esse indivíduo à mercê de si mesmo.

O processo de personalização é, portanto, uma nova maneira de a sociedade se organizar e se orientar, em que o que impera não é tanto a vinculação a uma determinada norma social, mas um processo em que as escolhas privadas são levadas ao extremo e o constrangimento deve sempre ser mínimo. 0 máximo de compreensão e o mínimo de coerção.

Ao invés de imergir o indivíduo dentro de regras uniformes de caráter moral, protecionista, o processo de personalização rompe com esse imaginário rigorista, cedendo lugar a novos valores que visam ao livre desenvolvimento da personalidade íntima, à legitimação do prazer, e agora à remodelagem das instituições de acordo com as aspirações dos indivíduos. O processo se inverte. Se, antes, a sociedade imperava sobre o indivíduo, agora o indivíduo quer que a sociedade seja de acordo com as suas aspirações.

Segundo Lipovetsky,

0 ideal moderno de subordinação do indivíduo a regras racionais coletivas foi pulverizado, 0 processo de personalização promoveu e encarnou maciçamente um valor fundamental: 0 da realização pessoal, do respeito à singularidade subjetiva, da personalidade incomparável, quaisquer que sejam as novas formas de controle e de homogeneização realizadas simultaneamente. O direito de ser absolutamente si mesmo, de aproveitar a vida ao máximo é, certamente, inseparável de uma sociedade que instituiu o indivíduo livre como valor principal e não é mais do que a manifestação definitiva da ideologia individualista; mas foi a transformação dos estilos de vida ligada à revolução de consumo que permitiu esse desenvolvimento dos direitos e desejos do indivíduo, essa mutação na ordem dos valores individualistas. Salto adiante da lógica individualista: o direito à liberdade - teoricamente ilimitado, mas até então circunscrito à economia, à política, à cultura - ganha os costumes e o cotidiano. Viver livre e sem pressões, escolher seu modo de existência são os pontos mais significativos no social e no cultural do nosso tempo, pontos da aspiração, do direito mais legítimo aos olhos dos nossos contemporâneos. (LIPOVETSKY, 2005, p. 18).

Ou ainda, segundo Bauman, que afirmará que o que caracterizaria a pós-modernidade seria a troca da segurança pela felicidade. Segundo Bauman,

Os homens e as mulheres pós-modernos trocaram um quinhão de suas possibilidades de segurança por um quinhão de felicidade. Os mal-estares da modernidade provinham de uma espécie de segurança que tolerava uma liberdade pequena demais na busca da felicidade individual. Os mal-estares da pós-modernidade provêm de uma espécie de liberdade de procura do prazer que tolera uma segurança individual pequena demais. (BAUMAN, 1998, p. 10). 
Essa nova configuração advinda do processo de personalização traz consigo um novo lugar para o indivíduo. Atualmente nenhum tipo de ideologia política é capaz de inflamar as multidões; os tabus, ainda que presentes, são mitigados a esferas privadas; os referenciais são perdidos e o vazio domina o indivíduo, mas esse vazio de forma alguma é um vazio trágico, e sim um vazio que vê no hiperconsumo uma saída para tal situação.

A era do consumismo se instaura como espécie de tentativa de lidar com essa nova configuração. Consumismo não apenas de coisas, mas do próprio modo de existência. Consumos de lazer, viagens, psicologias etc. $O$ que se busca é a qualidade de vida, sensibilidade ecológica, participações em feiras ao ar livre etc. O ideal do American way of life típico dos anos 20 do século passado é substituído por um novo ideal que tem no próprio indivíduo o seu alvo.

Segundo Bauman,

No mundo pós-moderno de estilos e padrões de vida livremente concorrentes, há ainda um severo teste de pureza que se requer seja transposto por todo aquele que solicite ser ali admitido: tem de mostrar-se capaz de ser seduzido pela infinita possibilidade e constante renovação promovida pelo mercado consumidor, de se regozijar com a sorte de vestir e despir identidades, de passar a vida na caça interminável de cada vez mais intensas sensações e cada vez mais inebriante experiência. (BAUMAN, 1998, p. 23).

O processo de personalização faz com que o individualismo se torne narcisista, isto é, o individualismo "limitado" se torne "total". No entanto, esse narcisismo não pode ser entendido como a instauração de um indivíduo monádico, mas ilustra para Lipovetsky outra dinâmica na hipermodernidade, que é o surgimento dos pequenos grupos com interesses comuns. Segundo ele,

O narcisismo não encontra seu verdadeiro sentido a não ser em uma escala histórica; no essencial, ele coincide com o processo tendencial que leva os indivíduos a reduzir a carga emocional investida no espaço público ou nas esferas transcendentes e, correlativamente, a aumentar as prioridades da esfera privada [...]. Do mesmo modo que o narcisismo não pode ser assimilado a uma estrita despolitização, ele é também inseparável de um entusiasmo relacional particular, como atesta a proliferação de associações, grupos de assistência e auxílio mútuo. A última figura do individualismo não reside numa independência soberana associal, mas sim nas ramificações e conexões em coletivos com interesses miniaturizados, hiperespecializados: reagrupamentos de viúvos, de pais de filhos homossexuais, de alcoólatras, de gagos, de mães lésbicas, de bulímicos. É preciso recolocar Narciso na ordem dos circuitos e redes integradas: solidariedade de pequenos grupos, participação e organização em trabalhos voluntários, "redes situacionais" não contradizem a hipótese do narcisismo, na verdade confirmam sua tendência. (LIPOVETSKY, 2005, p. 22-23). 
O individualismo que se inicia com o processo de personalização vê no narcisismo uma expressão dessa tendência social. 0 grande paradoxo é que, ao mesmo tempo em que o individualismo cresce, a sociedade se torna mais global. Aumenta-se o consumo de massa, a comunicação atinge praticamente todos os setores da vida e o senso de "pertença" do indivíduo diminui. O indivíduo hipermoderno se mostra cada vez mais em um não-lugar, fruto dessa nova configuração social. Em um espaço onde as ofertas são infinitas e os referenciais são cada vez menores, o indivíduo se encontra perdido, e é a partir disso que a sedução se torna a grande arma para o consumismo. $O$ indivíduo que não é mais coagido a nada tem que ser fisgado a partir da sedução. Tal sedução visa respeitar as inclinações e desejos do indivíduo na oferta de produtos que satisfaçam exatamente o que ele procura. As ofertas são a la carte, são feitas customizadas para o indivíduo. Desde os pacotes de viagem até o próprio automóvel, passando pelos processos educativos, as terapias psicológicas, médicas, os medicamentos, tudo é montado de acordo com o desejo do indivíduo visando à sua necessidade particular. A sedução não poupa nenhum aspecto da vida desse indivíduo hipermoderno, que não é mais dominado no sentido estrito da palavra, mas é agora colocado em uma "teia soft" onde se ilude pensando ser livre no infinito de escolhas possíveis.

Essa constante possibilidade de fazer-se a cada momento tem como consequência direta o fato de "desengajar" o indivíduo do sentimento de continuidade e até mesmo do sentimento de um sentido. A indiferença cresce em todos os setores da vida cotidiana. A palavra do professor deixa de ser sagrada, torna-se banal e situa-se em pé de igualdade com a palavra da mídia; 0 trabalho não é mais o centro da vida do indivíduo. Em uma sociedade onde a incredulidade em relação aos metarrelatos (para usarmos a expressão de Lyotrad) ${ }^{3}$ se faz presente de forma muito nítida, a apatia domina em todos os aspectos. Até mesmo movimentos como o retorno da esfera do sagrado, visíveis nas diversas novas formas de espiritualidades contemporâneas, indicam esse fluir apático da hipermodernidade. Segundo Lipovetsky,

O retorno do sagrado em si é atropelado pela celeridade e pela precariedade das existências individuais abandonadas a si mesmas. A indiferença pura designa a apoteose do temporário e do sincretismo individualista. Assim pode-se ser simultaneamente cosmopolita e regionalista, racionalista no trabalho e discípulo intermitente de determinado guru oriental; pode-se viver 0 momento permissivo e respeitar, de acordo com as necessidades, as prescrições religiosas. 0 indivíduo pós-moderno está desestabilizado e é, de certa maneira, "ubiquista". (LIPOVETSKY, 2005, p. 24).

${ }^{3}$ Cf. LYOTARD, Jean-François. A condição pós-moderna. Rio de Janeiro: José Olympio, 2004. 
Dessa forma, em um sistema que é organizado de acordo com o isolamento suave, "cool", os ideais públicos não têm outra alternativa a não ser o enfraquecimento, permanecendo apenas a busca do ego e dos próprios interesses por parte do indivíduo. Um hiperinvestimento do privado e uma desmobilização do espaço público. Segundo Lipovetsky, vemos "o fim do homo politicus e surgimento do homo psychologicus." (LIPOVETSKY, 2005, p. 33).

A principal característica desse movimento é a perda do sentido histórico. Nasce, nesse momento, toda uma cultura hedonista e psicologista que tem como meta incitar à satisfação imediata das necessidades e à urgência de todos os prazeres. Hoje se vive para si mesmo sem se preocupar com as tradições e muito pouco com a posteridade. A perda do sentido da continuidade histórica é uma marca desse individualismo narcisista que se instaura na hipermodernidade. Ao mesmo tempo em que o futuro aparece incerto, uma vez que a continuidade é colocada em xeque pelas constantes mudanças, o passado é desvalorizado por relembrar tradições e práticas arcaicas de controle. Esse indivíduo sem passado e sem futuro vê instaurar uma espécie de "narcisismo coletivo" que tem na apatia frívola uma de suas marcas mais visíveis. Desarraigado de tudo, esse indivíduo se encontra diante de um vazio e vê no autoinvestimento uma saída para tal vazio. Lipovetsky afirma que

Na verdade, o narcisismo foi gerado pela deserção generalizada dos valores e finalidades sociais, ocasionada pelo processo de personalização. A anulação dos grandes sistemas de sentidos e 0 hiperinvestimento do Eu andam de braços dados: nos sistemas com "aparência humana", que funcionam para o prazer, o bem-estar, a despadronização, tudo concorre para a promoção de um individualismo puro, ou seja, psicológico, desembaraçado dos enquadramentos de massa e projetado para a valorização geral do indivíduo. É a revolução das necessidades e sua ética hedonista que, atomizando suavemente os indivíduos e esvaziando aos poucos as finalidades sociais de seus significados profundos, permitiu que o discurso psi se enxertasse no social e se tornasse um novo éthos de massa; foi o "materialismo" exacerbado das sociedades da abundância que, paradoxalmente, tornou possível a eclosão de uma cultura centrada na expansão subjetiva, não por reação ou "suplemento de alma", mas sim, por isolamento à escolha de cada um. [...] Longe de derivar de uma "tomada de consciência" desencantada, o narcisismo é o efeito do cruzamento entre uma lógica social individualista hedonista, impulsionada pelo universo dos objetos e dos sinais, e uma lógica terapêutica e psicológica, elaborada desde o século XIX a partir da aproximação psicopatológica. (LIPOVETSKY, 2005, p. 34-35).

Se a análise lipovetskiana estiver correta, podemos afirmar que, no momento em que 0 crescimento econômico cessa, vemos crescer o investimento psicológico, em que o indivíduo passa a consumir "consciência de si" em um movimento incessante de autoconhecimento. Narciso, agora identificado como homo psychologicus, é obcecado por si mesmo visando à sua independência de todo laço com o outro. 
O autoconhecimento se torna a sina desse indivíduo, e daí pode-se perceber como a Psicanálise, com a noção de inconsciente, aparece como uma incrível ferramenta para esse indivíduo que precisa agora buscar, em uma aventura sem fim, se conhecer. Adentrar para as sendas inconscientes em uma busca frenética por sua verdade. 0 narcisismo se desamarra de todos os entraves. A autoconsciência substitui a consciência de classe, ao mesmo tempo em que a consciência narcisista toma o lugar da consciência política. No entanto, quanto mais se investe nesse autoconhecimento, mais dúvidas aparecem a esse indivíduo, e a incerteza o domina. Sem referências de onde se ancorar, Narciso se coloca em órbita. O Eu aparece como um grande vazio devido ao hiperinvestimento a ele dedicado. Paradoxalmente, nada e tudo o aflige. Segundo Lipovetsky,

A tese do "progresso" psicológico é insustentável diante da extensão e da generalização dos estados depressivos, outrora reservados em prioridade para as classes burguesas. Ninguém pode se vangloriar de escapar; a deserção social ocasionou uma democratização sem precedente da depressão, o tédio de viver, flagelo hoje em dia difundido e endêmico. Do mesmo modo, o homem "cool" não é mais sólido do que o homem do adestramento puritano ou disciplinar. Na verdade, seria mais o inverso. Num sistema descaracterizado basta um simples acontecimento, um nada, para que a indiferença se generalize e ganhe existência própria. Atravessando sozinho o deserto, levando a si mesmo sem qualquer apoio transcendental, o homem de hoje se caracteriza pela vulnerabilidade. A generalização da depressão deve ser levada em conta não das vicissitudes psicológicas de cada um ou das "dificuldades" da vida atual, mas, sim, da deserção da res publica que foi limpando o terreno até o advento do indivíduo puro, do Narciso em busca de si mesmo, obcecado por si mesmo e, assim sendo, suscetível de enfraquecer ou de desmoronar a qualquer momento diante da adversidade que enfrenta desarmado, sem força exterior. 0 homem descontraído está desarmado. Os problemas pessoais assumem, assim, dimensões desmesuradas, e, quanto mais os contemplamos, ajudados ou não pelos psi, menos os resolvemos. Aqui se inclui o problema existencial, o ensino ou a política: quanto mais submetidos a tratamento e auscultação, mais os problemas se tornam insuperáveis. 0 que, hoje em dia, não está sujeito à dramatização e ao estresse? Envelhecer, engordar, enfeiar, dormir, educar os filhos, sair de férias... tudo se transforma em problema. As atividades elementares se tornaram impossiveis. (LIPOVETSTKY, 2005, p. 29-30).

Esse sentimento de não pertença a nada de sólido caracteriza aquilo que Bauman chamou de "sociedade líquida", que aponta para uma fragilidade das relações humanas. Nela, o Outro é esvaziado em toda a sua espessura, torna-se indiferente. Esse Outro aparece como um ser desafeiçoado que, várias vezes, será usado apenas como mero objeto de gozo.

Esse Outro desafeiçoado se torna indiferente, mas ao mesmo tempo algo a ser temido. 0 desapego emocional cada vez maior em nosso tempo indica esse temor. 0 medo de se decepcionar faz com que o indivíduo não entre em relação com esse Outro como uma espécie de fuga diante do sentimento. 0 sexo transformado em algo cool visa tentar eliminar a tensão que a relação sexual envolve, visando com isso um ar de indiferença e de desapego. Em vez da relação 
humana que envolve um descortinar-se para o Outro por parte do indivíduo, Narciso prefere a busca de uma "experiência forte", em que amar e vibrar se encontram de maneira rápida e solitária. Nessa busca, o que encontra é a própria desolação e nada além disso.

O individualismo narcisista emerge e coloca o indivíduo diante desse grande vazio em que nenhuma referência se mostra sólida o bastante para o sustentar. Se o passado como senso histórico, tradição, pertença a um lugar se perdeu, se o futuro gera mais medo que esperança, o Outro aparece como algo a ser temido em vez de alguém a ser buscado; resta a esse indivíduo uma busca desenfreada por si mesmo, tornando tudo a seu redor mero algo a ser consumido para tentar aplacar o vazio que o assola.

\section{A Religião no contexto da hipermodernidade}

Feitas essas observações sobre a hipermodernidade, passamos agora a analisar esse lugar da Religião em uma época em que os referenciais estão em grande parte perdidos. É óbvio que a Religião ainda ocupa um lugar de destaque em nossa sociedade, e uma grande prova disso é o fato de que cada vez mais vemos surgir novas formas de espiritualidades nos grandes centros.

Cada dia mais as pessoas buscam formas de viver a sua religiosidade, e não é difícil de imaginar que essas diversas formas acabam não raras vezes sucumbindo à dinâmica hipermoderna e se tornando mais um objeto de consumo ou então se caracterizando por uma Religião a la carte. Práticas cada vez mais emocionais acabam por caracterizar muito a religiosidade contemporânea.

A Religião, nesse contexto, surge dentro do cosmos hipermoderno como uma tentativa de uma busca de sentido contra a insegurança das constantes mudanças que caracterizam tal momento social. $O$ indivíduo hipermoderno se sente inseguro. Os avanços tecnológicos que prometiam um mundo melhor, mesmo com todos os progressos feitos em diversas áreas, não foram capazes de cumprir sua promessa, sendo várias vezes usados para fins contrários à vida humana. Por exemplo, a energia nuclear, que é usada como instrumento de destruição e ameaça a sobrevivência da humanidade; a manipulação genética, que gera um desequilíbrio na biosfera, dentre outras coisas.

Da mesma forma, as propostas de um mundo melhor feitas pelas ideologias modernas tais como a democracia liberal, o socialismo marxista ou o racionalismo científico se mostraram insuficientes para cumprir a promessa de um mundo melhor e tiveram que ser abandonadas, revelando o grande vazio da existência voltada agora para a satisfação das necessidades 
imediatas. Essa satisfação sempre imediata, com o passar do tempo, mostra toda a sua incompletude e faz com que o indivíduo se volte para uma busca de valores que transcendam a banalidade do cotidiano e, ao mesmo tempo, ofereçam algum tipo de sentido à existência.

Em meio às diversas incertezas, cresce a necessidade de um sentido, de segurança, e até mesmo de uma identidade comunitária. O movimento de secularização advindo do século XIX atinge até mesmo a Religião, de forma que o que se vê cada dia mais forte é o surgimento de um religioso progressivamente mais desinstitucionalizado, subjetivo e afetivo.

Em um mundo onde tudo é questionado, obviamente a relação do indivíduo com a instituição aparecerá como um objeto a também ser questionado. Na medida em que a instituição não mais condiz com as suas convicções, esse indivíduo se sente mais que no direito de sair e procurar uma outra, ou até mesmo de não se filiar a nenhuma outra instituição, mas ainda assim mantém para si a filiação a determinado discurso religioso.

Tal movimento é muito comum entre os evangélicos neopentecostais, que têm como prática constante a dissidência de uma instituição e a formação de outra, com poucos membros, que se propõe a ser uma nova igreja, onde os erros do passado não serão cometidos. Um caso famoso disso é a igreja do missionário R.R. Soares, que é dissidência da Igreja Universal do Reino de Deus, de Edir Macedo.

Esse processo de desinstitucionalização da Religião evidencia, a nosso ver, que o discurso religioso se tornou aberto e flexível, uma questão de cunho individual, que está aberta a mudanças quantas vezes se fizer necessárias. A Religião acaba por perder o seu caráter comunitário e se torna ela mesma algo a ser assimilada pelo próprio sujeito hipermoderno. A Religião se torna individual, sucumbe ao individualismo, e percebe-se que várias vezes o que rege a relação do indivíduo com a Religião escolhida é o nível de emoção e satisfação que ela é capaz de propiciar.

Podemos perceber essa dinâmica novamente nas igrejas evangélicas neopentecostais. Basicamente são duas tônicas que se percebem claramente nessas igrejas: 0 apelo emocional de cunho várias vezes midiático, e a sua vinculação estrita à chamada Teologia da Prosperidade. Tal "Teologia", fundada por volta dos anos 1950 nos Estados Unidos, propõe que o desejo de Deus para com seus filhos é que eles adquiram riquezas materiais como prova de que Deus está entre eles. Deus, sendo o detentor de todas as coisas, tem prazer em que seus filhos desfrutem das bênçãos deste mundo. Partindo de uma Leitura não-tradicional do texto bíblico, principalmente do 
texto do profeta Malaquias ${ }^{4}$, tal Teologia propõe uma relação mercantil para com Deus de forma que as bênçãos divinas estarão à disposição do fiel na medida em que o fiel se dispõe a contribuir com o "reino de Deus". Tal contribuição é de ordem financeira e se restringe, na maior parte das vezes, a ofertas a determinada instituição.

A fé do indivíduo é "medida" pela disposição demonstrada em contribuir. Quem contribui mais tem mais fé, quem contribui menos está em dúvida em relação ao que Deus pode fazer. Percebe-se claramente que tal Teologia tem um caráter completamente mercantil, visando transformar a fé e a relação do homem com Deus em uma relação de troca, em que o que é consumido pelo indivíduo não é tanto um "produto", mas uma relação. Nesse sentido, percebe-se, pelo que já foi dito nesse trabalho, que tal Teologia se vincula de forma bem próxima à dinâmica hipermoderna de consumo.

O outro caráter das igrejas evangélicas neopentecostais é a ênfase nas emoções vividas durante os cultos. O pastor ou líder da comunidade geralmente possui um discurso eloquente e inflamado que visa incitar nos fiéis o mesmo frenesi que se encontra nele. Por meio de orações cada vez mais fortes, o líder procura fazer com que os fiéis "sintam" a presença de Deus. A ênfase no milagre e no "mover de Deus" é uma grande tônica desse tipo de culto. Deus deve agir aqui e agora para mostrar a sua presença. Esse imediatismo da ação é o que mostrará ao fiel que a sua prática está correta e que ele está agindo de acordo com a vontade de Deus, uma vez que 0 próprio milagre só sucederá se houver, por parte do fiel, um coração limpo e sem pecado para com Deus. Qualquer mácula é um empecilho para que Deus aja na vida do fiel.

Consumismo e foco em uma ação presente caracterizam esse culto das igrejas evangélicas neopentecostais, e isso também são características marcantes da hipermodernidade, como tratamos mais acima neste trabalho. Além disso, percebemos que nessas igrejas há a predominância de um discurso mais rígido em relação à moralidade sexual, e também uma exaltação muito grande da figura do líder, de forma que várias vezes o próprio fiel abre mão de sua individualidade em função de uma adesão ao discurso do líder ou às diretrizes da igreja.

Percebe-se claramente que essa forma de Religião tem na hipermodernidade a sua ancoragem e pretende dar conta dessa nova configuração. Ao mesmo tempo em que coloca o fiel em uma relação com uma espécie de transcendência, não abre mão da relação mercantil/emocional. O próprio transcendente é transformado em algo a ser consumido intensamente pelo fiel.

${ }^{4}$ Cf. Bíblia Sagrada. Tradução King James. Disponível em: https://www.bibliaonline.com.br/kjv. Acesso em: 29 Junho. 2018. 
No entanto, apesar de as igrejas neopentecostais serem as mais numerosas no Brasil, não podemos cometer a falácia de tomar a parte pelo todo. Sabemos que há diversas outras instituições religiosas que não aderem às práticas neopentecostais e que não fazem uso da Teologia da Prosperidade. As instituições mais tradicionais, como a presbiteriana, a luterana, a metodista, dentre outras, mantêm uma tônica diferente daquelas igrejas. Algo interessante a se notar nessa pequena análise a que nos propomos é que a Religião não pode ser reduzida a seu caráter institucional. Qualquer tentativa de análise da Religião que se prenda apenas ao nível institucional comete o erro de tomar a parte pelo todo. Rubem Alves propõe que

Descrever a experiência religiosa tomando suas cristalizações institucionais e dogmáticas como ponto de referência é o mesmo que tentar compreender a vida através do cadáver. Existe um abismo entre as formas reificadas da Religião e a experiência que lhes deu origem. Poder-se-á compreender 0 amor pela instituição do casamento? O mesmo podemos dizer da infinita distância que separa a experiência religiosa, essencialmente emocional e existencial, dos objetos que eventualmente surgiram desta experiência. (ALVES, 2007, p. 160).

Se a Religião fosse equivalente apenas às suas "cristalizações institucionais e dogmáticas", provavelmente críticas como as propostas por Marx, que propunha que a Religião seria uma espécie de "ópio do povo"5, seriam uma boa forma de compreendê-la. Mas Alves aponta em outra direção. A base da Religião está em seu caráter humano, que é esquecido com a ênfase apenas na institucionalização. Com a institucionalização, o que se vê é o estabelecimento de uma estrutura altamente repressora, que nega o homem em detrimento dos dogmas aceitos pela instituição.

Mas se a Religião transcende a sua forma institucionalizada e se caracteriza por ser uma forma de o sujeito lidar com o mundo, há algo nessa dinâmica que escapa à nossa análise e que não pode ser dito tomando apenas o seu caráter de vínculo com a hipermodernidade. A força da Religião, mesmo na hipermodernidade, deve ser buscada em um outro lugar que não em sua análise sociológica. Faz-se necessária uma busca pelo caráter humano da Religião que se expressa culturalmente para além do seu vínculo com a hipermodernidade.

O discurso religioso na época da hipermodernidade, portanto, mostra-se de forma dual. Se por um lado vemos um discurso institucional se aliando a uma dimensão mercantil da fé, podemos perceber também o surgimento de um discurso que se volta para o indivíduo - mas não

\footnotetext{
${ }^{5}$ Cf. MARX, Karl \& ENGELS, Friedrich. A ideologia alemã. 2 ed. São Paulo: Editora Ciências humanas, 1979. 138 p. e também MARX, Karl. Manuscritos Econômicos Filosóficos In: FROMM, Erich. O conceito marxista de homem. Rio de Janeiro: Zahar Editores, 1964. 233 p.
} 
o fazendo fechar-se sobre si mesmo em uma atitude narcisista, como propõem as Leituras mais próximas da Teologia da Prosperidade, porém abrindo para uma dimensão transcendente. Não uma transcendência qualquer, mas uma transcendência em direção a um Outro como lugar de expressão de uma Religião autêntica.

Se o desencantamento do mundo é um dado com que não podemos deixar de lidar, é preciso que a Religião não seja apenas uma tentativa nostálgica, vã, de retomar uma espécie de metafísica medieval, mas seja uma tentativa de se abrir para o Outro, vendo esse Outro como um ser que transcende ao indivíduo.

Se a hipermodernidade aparece como o lugar de uma hiper-individuação e de um fechamento do sujeito sobre si mesmo, a Religião entendida conforme propomos se mostra como uma grande subversão, em que a figura do Outro aparecerá depois de ser negada pelo discurso vigente. Se os referenciais se perdem na hipermodernidade, o mesmo não se pode dizer da relação do indivíduo com o seu próximo. Esta se mantém, mesmo que fragilizada, e talvez a Religião possa dar consistência a essa relação Eu-Tu no interior da hipermodernidade.

Obviamente, as duas vias apontadas por nós neste trabalho, a saber, a espiritualidade mais centrada no sujeito e a adesão de forma mais rígida a um discurso, tal como o da Teologia da Prosperidade, não caracterizam completamente aquilo que estamos chamando de discurso religioso na época da perda dos referenciais. Tal perda provoca no sujeito hipermoderno um novo tipo de busca que pode se evidenciar em uma internalização extrema desta busca, como no caso citado da "nova era", como também pode encontrar vazão em um tipo de discurso mais totalitário, como vemos acontecer em algumas esferas do catolicismo e do protestantismo e foi ilustrado por nós a partir do neopentecostalismo evangélico. As duas vias para essa relação do sujeito com a dimensão religiosa evidenciam, a nosso ver, duas faces da mesma moeda, qual seja, a busca de um norte para si em um mundo onde os referenciais se mostram evaporados.

\section{Referências}

ALVES, Rubem. $O$ enigma da Religião. 6 ed. Campinas: Papirus, 2007

BAUMAN, Zygmunt. O Mal-estar da Pós-Modernidade. Rio de Janeiro: Jorge Zahar, 1998.

BÍBLIA SAGRADA. Tradução King James. Disponível em https://www.bibliaonline.com.br/kjv.

DUMONT, Louis. Homo aequalis: gênese e plenitude da ideologia econômica. Tradução de José Leonardo Nascimento. Bauru: EDUSC, 2000. 280 p. 
DUMONT, Louis. Homo hierarchicus: o sistema das castas e suas implicações. São Paulo: EDUSP, 1992. 412p.

DUMONT, Louis. O individualismo: uma perspectiva antropológica da ideologia moderna. Rio de Janeiro: Rocco, 1985.

KUMAR, Krishan. Da sociedade Pós-Industrial à pós-Moderna. Novas teorias sobre o mundo contemporâneo. Tradução de Ruy Jungmann. Rio de Janeiro: Jorge Zahar Editor, 1997.

LIPOVETSKY, Gilles; CHARLES, Sébastien. Os tempos hipermodernos. São Paulo: Barcarolla, 2004

LIPOVETSKY, Gilles. A era do vazio: ensaios sobre o individualismo contemporâneo. Tradução de Therezinha Monteiro Deutsch. Barueri: Manole, 2005.

LIPOVETSKY, Gilles. A felicidade paradoxal: ensaio sobre a sociedade de hiperconsumo. São Paulo: Companhia das Letras, 2007

LYOTARD, Jean-François. A condição pós-moderna. Rio de Janeiro: José Olympio. 2004.

MARX, Karl \& ENGELS, Friedrich. A ideologia alemã. 2 ed. São Paulo: Editora Ciências humanas, 1979. 138 p. e também MARX, Karl. Manuscritos Econômicos Filosóficos In: FROMM, Erich. 0 conceito marxista de homem. Rio de Janeiro: Zahar Editores, 1964. 